\title{
Modul Keragaman Genetik dan Fenotipik Kedelai Berbasis Inkuiri untuk Siswa SMK
}

\author{
Rosita Ariyanti $^{1}$, Siti Zubaidah ${ }^{1}$, Heru Kuswantoro ${ }^{1}$ \\ ${ }^{1}$ Pendidikan Biologi-Universitas Negeri Malang
}

\begin{tabular}{l}
\hline \hline INFO ARTIKEL \\
\hline Riwayat Artikel: \\
Diterima: 27-06-2019 \\
Disetujui: 15-02-2020 \\
\hline
\end{tabular}

\section{Kata kunci:}

genetic diversity; phenotype diversity; soy; keragaman genetik; keragaman fenotip; kedelai

\begin{abstract}
ABSTRAK
Abstract: The study was conducted to produce inquiry-based modules on genetic and phenotypic variabilities of soybeans hybrid from crosses of CpMMV resistant strains and Grobogan. This development research using ADDIE development model (Analyze, Design, Develop, Implement, and Evaluate). The research sample was 32 students from the ATPH class 3 of SMK 1 Tulungagung. Data collection uses validation sheets, questionnaires and observation sheets. The results showed that the module was valid or feasible to use with the results of the calculation of material experts $88.28 \%$, media experts $98.2 \%$, field practitioners $97.66 \%$, the results of the trial showed module readability $83.5 \%$, it can be concluded that module is feasible to be used and disseminated.
\end{abstract}

\begin{abstract}
Abstrak: Penelitian dilakukan untuk menghasilkan modul berbasis inkuiri tentang keragaman genetik dan fenotipik kedelai hasil persilangan Grobogan dan galur tahan CpMMV. Jenis penelitian ini merupakan penelitian pengembangan dengan beracuan pada model pengembangan ADDIE (Analyze, Design, Develop, Implement, dan Evaluate). Sampel penelitian sebanyak 32 siswa dari kelas ATPH 3 SMKN 1 Tulungagung. Pengumpulan data peneltian menggunakan lembar validasi, angket dan lembar observasi. Hasil penelitian menunjukkan bahwa modul dinyatakan valid atau layak digunakan dengan hasil perhitungan ahli materi 88,28\%, ahli media 98,2\%, praktisi lapangan $97,66 \%$, hasil uji coba menunjukkan keterbacaan modul 83,5\%. Kesimpulannya modul sudah layak untuk digunakan dan disebarluaskan.
\end{abstract}

\author{
Alamat Korespondensi: \\ Rosita Ariyanti \\ Pendidikan Biologi \\ Universitas Negeri Malang \\ Jalan Semarang 5 Malang \\ e-mail: rositariyanti.139@gmail.com
}

Pendidikan Menengah Kejuruan merupakan wadah yang mempersiapkan siswa agar dapat bekerja dengan baik pada bidang tertentu (Undang Undang No 20 Tahun 2003). Hal tersebut dapat tercapai apabila sistem pembelajaran yang diterapkan mampu meningkatkan keterampilan siswa sehingga lulusan yang dihasilkan sudah siap kerja. Pembelajaran difokuskan pada pencapaian pengetahuan, sikap dan keterampilan yang diperlukan di dunia kerja (Damarjati, 2016). Depdiknas sudah menyusun pendidikan dengan orientasi kecakapan hidup (life skill) yang terfokus pada satu bidang sehingga setiap siswa akan memiliki keahlian di bidang tertentu (Murti, 2013). Keterampilan siswa dalam suatu bidang akan meningkat seiring dengan bertambahnya pemahaman siswa terhadap materi yang dipelajari (Juniarta, 2016). Keterampilan maupun pemahaman terhadap suatu hal akan lebih efektif jika pembelajaran ditunjang dengan penggunaan bahan ajar yang tepat (Effiong, Ekpo, \& Charles, 2015; Mushtag \& Khan, 2012).

Hasil analisis kebutuhan yang dilakukan di SMKN 1 Tulungagung menunjukkan bahwa siswa memerlukan bahan belajar yang lengkap, materi mendalam dan disajikan per topik sehingga membantu menguasai konsep secara lebih matang. Bahan ajar yang cocok digunakan untuk membelajarkan materi adalah yang tercetak karena lebih fleksibel dalam menyampaikan informasi dan memungkinkan pembaca mengulang bacaannya, jenisnya juga ada berbagai macam yakni buku, handout, modul, LKS, dan brosur (Azhar, 2002). Diantara jenis tersebut yang memiliki kelebihan dalam penyampaian materi yang lengkap, mendalam, spesifik, dan dapat digunakan tanpa bantuan penuh dari guru adalah modul (Unesco, 1977). Modul dapat digunakan untuk meningkatkan hasil belajar kognitif (Adnyana, Budi, \& Citrawathi, 2017; Qodriyani, Sukiya, \& Wibowo, 2017), selain itu juga mampu membangkitkan motivasi (Ismulyati, Khaldun, \& Munzir, 2015), sikap spiritual (Qodriyani et al., 2017), dan keterampilan proses sains (Adnyana et al., 2017; Sodikun, Sugiyarto, \& Prayitno, 2015).

Modul dikembangkan dengan mengintegrasikan model pembelajaran sebagai kerangka utama yang membantu mengarahkan kegiatan siswa. Model pembelajaran yang cukup efektif adalah inkuiri karena sejalan dengan kompetensi pada SMK yang lebih mengarah pada pendekatan praktik. Proses belajar berbasis inkuiri akan mampu meningkatkan pemahaman siswa (Andrini, 2016; Salim, 2015). Kegiatan inkuiri akan mengarahkan cara berpikir siswa dimulai dari munculnya suatu 
konflik kognitif yang dapat memicu rasa ingin tahu sehingga siswa akan menelusuri informasi secara mandiri untuk menemukan konsep yang benar. Penggunaan modul dengan berbasis inkuiri akan memudahkan siswa untuk belajar lebih efektif. Hal tersebut juga ditunjang dengan hasil penelitian yang menunjukkan bahwa modul berbasis inkuiri terbimbing efektif dalam meningkatkan hasil belajar (Ikhsan, Sutarno, \& Prayitno, 2016; Rohmiyati, Ashadi, \& Utomo, 2016). Hasil penelitian menunjukkan bahwa penggunaan modul yang berbasis inkuiri terbimbing juga efektif dalam meningkatkan berbagai keterampilan siswa diantaranya keterampilan proses sains (Dewi, Suyatna, \& Ertikanto, 2017; Sugiyarto \& Prayitno, 2015) dan keterampilan berpikir kritis (Prihatin, Prayitno, \& Rinanto, 2017) karena didalam modul inkuiri terbimbing terdapat pengalaman belajar yang mendukung ketercapaian keterampilan tersebut.

Konten materi yang perlu dipelajari siswa SMK di bidang pertanian sangat luas, seiring dengan berkembangnya ilmu maka informasi yang diperoleh juga harus diperbarui. Ilmu terkini dapat diperoleh dari hasil penelitian diantaranya terkait dengan keragaman genetik dan fenotipik kedelai. Informasi terkait hal tersebut sangat penting karena kedelai merupakan salah satu jenis tanaman pangan yang cukup banyak dikonsumsi oleh masyarakat Indonesia (Aimon \& Satrianto, 2015; Kementerian Pertanian, 2016). Permintaan kedelai cukup tinggi yakni sebesar 2,2 juta ton akan tetapi produksi di Indonesia belum mampu mencukupi (Manurung, 2003) sehingga masih perlu dilakukan impor kedelai (Benny, 2011) sebanyak 67,99\% dari total nilai pemenuhan kebutuhan kedelai (Kementerian Pertanian, 2016). Salah satu cara meningkatkan produktivitas kedelai adalah dengan melakukan pemuliaan tanaman untuk memperoleh bibit tanaman unggul. Tahapan dalam proses pemuliaan tanaman meliputi tahap seleksi untuk memilih karakter atau sifat yang diinginkan (Hapsari, 2014; Terryana et al., 2017), uji daya hasil, dan uji adaptasi di berbagai lokasi (Terryana et al., 2017). Faktor penting dalam tahap seleksi untuk menilai ekspresi sifat dan menentukan individu yang terpilih adalah keragaman genetik dan fenotipik (Hutami, Mariska, \& Supriati, 2006; Jambormias, Sutjahjo, Jusuf, \& Suharsono, 2004; Saleh, Abdullah, \& Anuar, 2002). Keragaman genetik menunjukkan keragaman gen dalam menentukan sifat yang muncul, sedangkan keragaman fenotipik menunjukkan adanya ragam lingkungan atau interaksi antara genetik dan lingkungan yang dapat berpengaruh pada kemunculan suatu sifat (Kuswantoro, Artari, Rahajeng, Ginting, \& Agus, 2018).

Penggunaan modul yang memuat informasi hasil penelitian diharapkan dapat memenuhi kebutuhan sumber belajar dan menambah pemahaman siswa terkait materi sehingga mampu meningkatkan keterampilan bidang siswa. Berdasarkan hal yang telah dijabarkan maka perlu dilakukan penelitian dengan tujuan mengembangkan modul keragaman genetik dan fenotipik hibrida F1 hasil persilangan varietas Grobogan dengan galur tahan CpMMV.

\section{METODE}

Penelitian ini merupakan penelitian pengembangan dengan beracuan pada model ADDIE yang terdiri dari lima tahap, yaitu analisis (analysis), desain (design), pengembangan (development), implementasi (implementation), dan evaluasi (evaluation) (Branch, 2009). Alasan pemilihan model ADDIE karena lebih sederhana, namun efisien dalam mengembangkan produk. Penelitian dilaksanakan bulan April 2019 di SMKN 1 Tulungagung. Sampel penelitian sebanyak 32 siswa dari kelas ATPH 3, dipilih dengan teknik purposive sampling. Data dikumpulkan dengan menggunakan lembar validasi dan angket uji keterbacaan.

\section{HASIL}

Produk yang telah dikembangkan adalah modul keragaman genetik dan fenotipik kedelai hasil persilangan yang berbasis pada model pembelajaran inkuiri. Hasil validasi modul oleh ahli dan hasil uji coba dijabarkan sebagai berikut.

\section{Deskripsi Sajian Produk}

Produk yang dikembangkan berupa modul pembelajaran berbasis inkuiri tentang keragaman genetik dan fenotipik. Modul dilengkapi dengan halaman sampul, kata pengantar, daftar isi, profil modul, pendahuluan, petunjuk penggunaan, unit belajar, glosarium dan daftar rujukan. Modul yang dikembangkan tersusun atas tiga unit belajar, komponen ini merupakan bagian utama modul. Setiap unit belajar tersusun atas tujuan pembelajaran, kegiatan belajar, review materi, rangkuman, latihan mandiri, rubrik penilaian dan kolom skor. Kegiatan belajar yang terdapat pada modul menggunakan langkah kegiatan model pembelajaran inkuiri. 


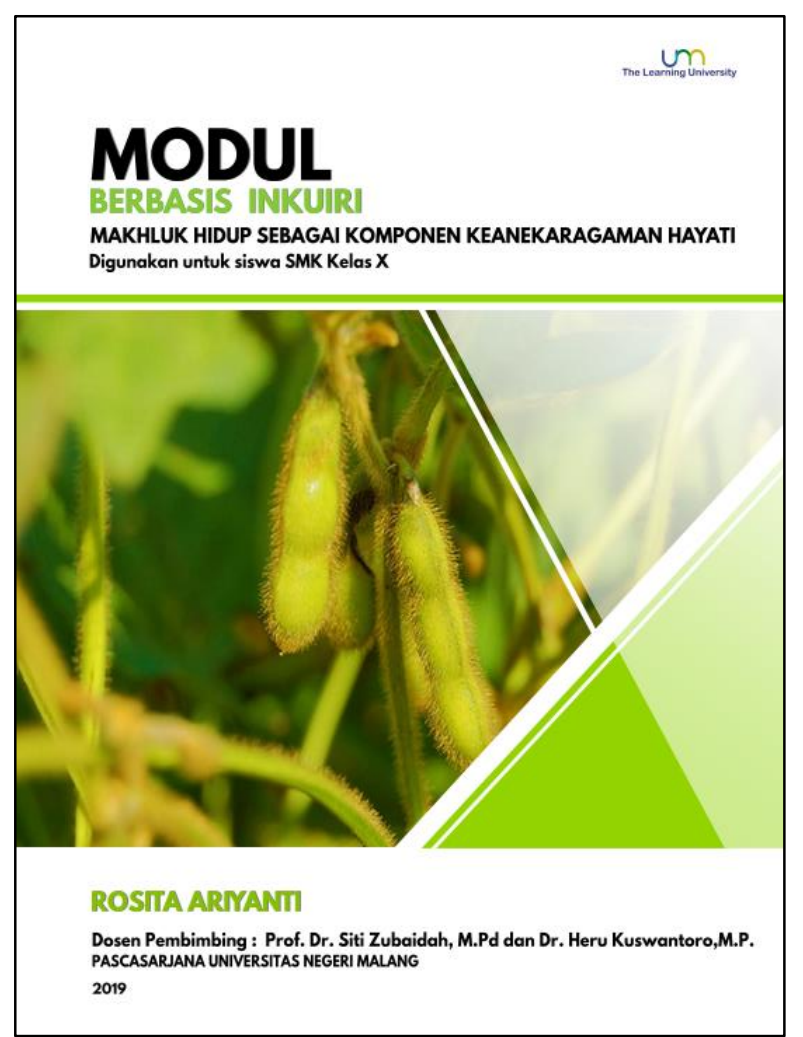

(a)

Unit Belajar 2
KOMPONEN KEANEKARAGAMAN HAYATI
Tujuan pembelajaran :
1. Siswa mampu mengaitkan ciri dan sifat makhluk hidup dengan perannya sebagai komponen dalam keane-
karagaman hayati
2. Siswa mampu membedakan makhluk hidup berdasarkan ciri, sifat, dan habitat sebagai komponen dalam
keanekaragaman hayati
AYO BELAJAR !
Jenis makhluk hidup yang dapat kita jumpai sangat beraneka ragam. Setiap makhluk hidup
memiliki ciri tersendiri sehingga terbentuklah keanekaragaman makhluk hidup. Keane-
karagaman makhluk hidup disebut sebagai keanekaragaman hayati atau biodiversitas.
Indonesia termasuk negara yang memiliki biodiversitas besar di dunia.
MENGEKSPLORASI FENOMENA
Perhatikan Fenomena berikut secara seksama
Kedelai merupakan salah satu komoditas bahan pangan utama di Indonesia selain
padi dan jagung. Kedelai umumnya diolah menjadi berbagai produk seperti tempe, tahu,

(b)

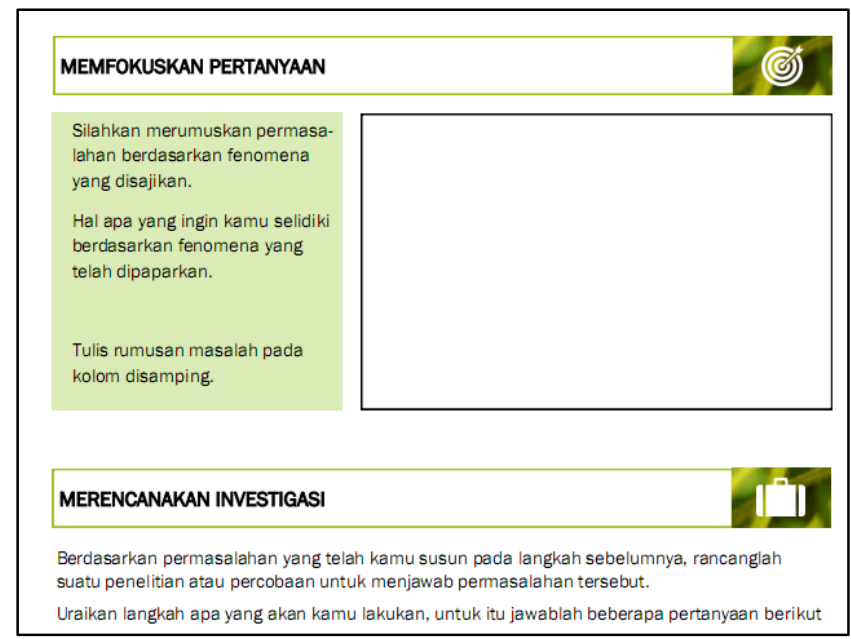

(c) 


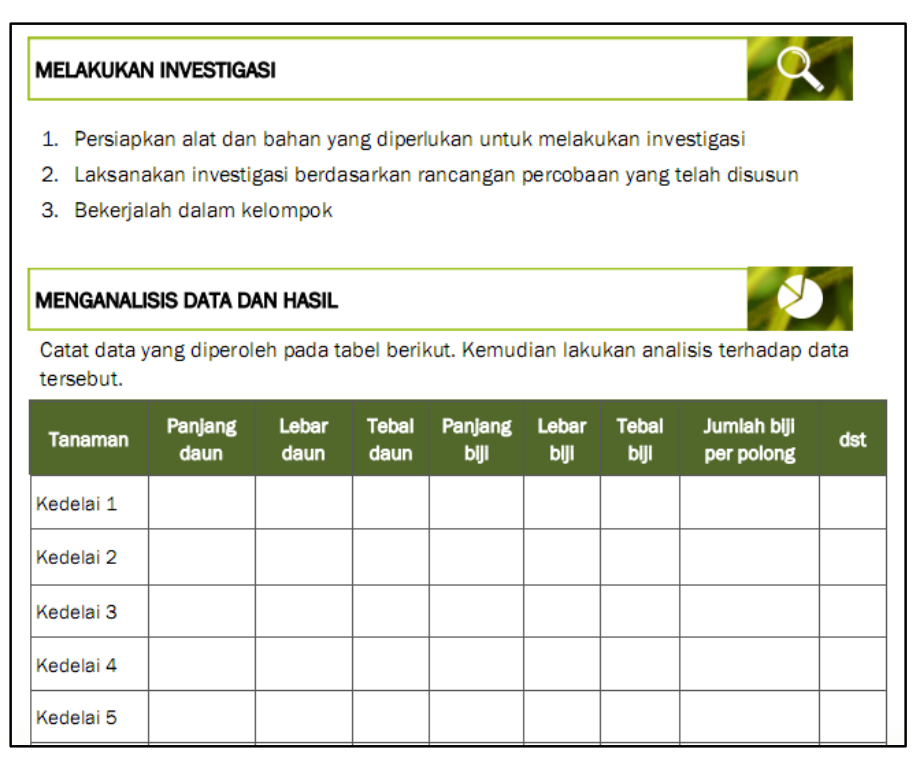

(d)

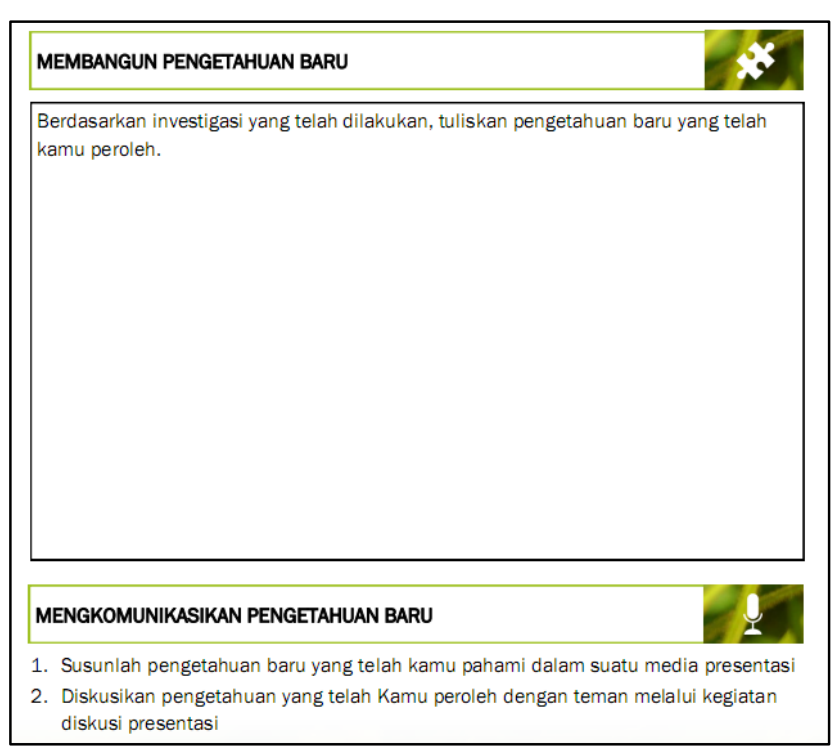

(e)

Gambar 1. Contoh desain tampilan modul. Gambar (a) merupakan cover modul, gambar (b) sampai (e) merupakan tampilan sintaks pembelajaran

\section{Data Hasil Validasi Materi}

Ketepatan materi dalam modul divalidasi oleh dosen Jurusan Biologi Universitas Negeri Malang, hasil validasi tercantum pada tabel 1. Rerata keseluruhan nilai validasi materi sebesar 95,21\% dengan kriteria sangat valid. Saran yang diberikan validator yaitu ada beberapa gambar yang perlu diperjelas dan akan lebih baik apabila ditambahkan ilustrasi. Selain itu, ada beberapa materi yang masih perlu direvisi.

Tabel 1. Ringkasan Data Validasi dari Segi Materi

\begin{tabular}{clc}
\hline No & \multicolumn{1}{c}{ Indikator } & Persentase \\
\hline 1 & Kesesuaian Materi dengan KD & $100 \%$ \\
\hline 2 & Keakuratan materi & $88,46 \%$ \\
\hline 3 & Kedalaman materi & $75 \%$ \\
\hline 4 & Kekontekstualan materi & $91,67 \%$ \\
\hline 5 & Kemutakhiran materi & $75 \%$ \\
\hline 6 & Mendorong keingintahuan & $100 \%$ \\
\hline 7 & Penyajian materi & $85 \%$ \\
\hline & Rerata Keseluruhan Nilai & $88,28 \%$ \\
\hline
\end{tabular}

\section{Data Hasil Validasi Media}

Validasi dari segi media dilakukan oleh dosen Jurusan Teknologi Pendidikan Universitas Negeri Malang. Rerata keseluruhan nilai validasi media yaitu 95,9375\% dengan kriteria sangat valid. Saran dari validator yaitu sebaiknya kertas yang digunakan adalah art paper sehingga tidak menyerap warna dan menghasilkan gambar yang lebih jelas. Hasil validasi tercantum pada tabel 2 .

Tabel 2. Ringkasan Data Validasi dari Segi Media

\begin{tabular}{clc}
\hline No & \multicolumn{1}{c}{ Indikator } & Persentase \\
\hline 1 & Self Instruction & $96,875 \%$ \\
2 & Self contained & $83,33 \%$ \\
3 & Stand alone & $100 \%$ \\
4 & Adaptif & $100 \%$ \\
5 & User friendly & $100 \%$ \\
\hline & Rerata keseluruhan nilai & $98,2 \%$ \\
\hline
\end{tabular}




\section{Data Hasil Validasi Praktisi Lapangan}

Validasi untuk menilai kepraktisan penggunaan modul dalam pembelajaran dilakukan oleh guru Biologi di SMKN 1 Tulungagung, hasil validasi tercantum pada tabel 3. Rerata keseluruhan nilai validasi oleh praktisi lapangan yaitu 97,66\% dengan kriteria sangat valid. Saran yang diberikan validator yakni penggunaan alokasi wkatu sebaiknya lebih disesuaikan karena pembelajaran di SMK memiliki 12 sampai 14 KD dalam satu tahun sehingga untuk satu KD hanya dapat menggunakan 2-3 jam pelajaran. Selain itu, materi yang dijabarkan pada modul juga masih terlalu dalam sehingga perlu ditinjau kembali

Tabel 3. Ringkasan Data Validasi oleh Praktisi Lapangan

\begin{tabular}{clc}
\hline No & \multicolumn{1}{c}{ Indikator } & Persentase \\
\hline 1 & Kelayakan penyajian & $90,63 \%$ \\
2 & Kelayakan isi & $100 \%$ \\
3 & Kelayakan bahasa & $100 \%$ \\
4 & Kesesuaian sintaks dengan isi & $100 \%$ \\
& Rerata keseluruhan nilai & $97,66 \%$ \\
\hline
\end{tabular}

\section{Data Hasil Uji Coba}

Uji keterbacaan dengan menggunakan angket yang berisi beberapa aspek diantaranya aspek kemenarikan, kelengkapan modul, dan kemudahan modul untuk dipahami. Secara keseluruhan nilai keterbacaan modul oleh siswa sebesar 83,5\%, nilai tersebut masuk dalam kategori cukup praktis dan memerlukan sedikit revisi. Aspek kemenarikan modul memperoleh nilai tertinggi dibandingkan dengan aspek lainnya yakni sebesar $85 \%$. Sementara itu, aspek kelengkapan memiliki nilai keterbacaan sebesar $81,05 \%$ dan aspek kemudahan untuk dipahami sebesar $83,5 \%$.

\section{PEMBAHASAN}

Produk yang telah dikembangkan berupa modul keragaman genetik dan fenotipik kedelai hasil persilangan yang berbasis pada model pembelajaran inkuiri. Modul merupakan bahan ajar yang memuat informasi terkait suatu topik, kegiatan pembelajaran dan instrumen evaluasi (Goldschmid \& Goldschmid, 1973). Modul beracuan pada kurikulum, artinya dikembangkan dengan menjabarkan capaian pembelajaran berdasarkan kompetensi inti dan kompetensi dasar (Kunandar, 2009) serta bersifat spesifik dan mendalam meskipun disajikan dalam uraian yang singkat (Lasmiyati \& Harta, 2014). Modul berisi kegiatan pembelajaran yang menerapkan model inkuiri. Penerapan pembelajaran inkuiri dapat mendorong siswa untuk lebih aktif melakukan suatu tindakan dalam rangka menemukan dan memahami suatu konsep belajar (Anam, 2015). Siswa dapat menggali informasi lebih jauh dan merancang suatu langkah untuk memverifikasi suatu informasi melalui inkuiri (Lahadisi, 2014). Sintaks inkuiri dimasukkan pada setiap unit belajar sehingga pembelajaran dapat dilakukan secara mandiri oleh siswa (Prihatin et al., 2017), meliputi eksplorasi fenomena, memfokuskan pertanyaan, merencanakan investigasi, melakukan investigasi, analisis data dan hasil, membangun pengetahuan baru, mengomunikasikan pengetahuan baru (Llewellyn, 2013). Pengalaman belajar yang diperoleh dari kegiatan inkuiri membentuk suatu konsep dengan pemahamannya sendiri terkait kompetensi dipelajari (Budiono \& Susanto, 2006).

Data hasil validasi yang diperoleh di lapangan menunjukkan bahwa modul sudah valid baik dari segi materi, media maupun kepraktisan (Ikhsan, Sutarno, \& Prayitno, 2016; Rohmiyati et al., 2016; Sodikun et al., 2015). Validasi materi memperoleh nilai sebesar $88,28 \%$ artinya materi yang disajikan sudah valid untuk digunakan, meskipun demikian masih ada sedikit revisi yang perlu dilakukan (Arikunto, 2010). Validitas materi meliputi tujuh aspek, dan diantara ketujuh aspek tersebut yang memperoleh nilai tertinggi dan masuk kategori sangat valid adalah aspek kesesuaian materi dengan KD dan aspek mendorong keingintahuan. Materi yang dijabarkan sudah sesuai dengan kompetensi dasar sehingga hal ini menunjukkan bahwa melalui penggunaan modul sudah mampu mencapai tujuan pembelajaran (Departemen Pendidikan Nasional, 2008). Keingintahuan siswa dapat terdorong karena adanya informasi yang unik dan menarik. Rasa ingin tahu yang tinggi mampu meningkatkan efektivitas pembelajaran karena siswa cenderung lebih antusias untuk belajar (Kashdan et al., 2009). Aspek berikutnya yang termasuk kategori sangat valid yakni kontekstual materi. Penyusunan modul didasarkan pada informasi yang ada pada kehidupan nyata (Nurrohman, Zubaidah, \& Kuswantoro, 2017). Informasi yang kontekstual mampu meningkatkan proses belajar siswa karena penggambarannya akan lebih nyata serta mudah dikaitkan dengan pengalaman siswa (Santoso, 2017). Aspek keakuratan dan kedalaman materi masuk dalam kategori valid, artinya materi cukup akurat dan mendalam, meski demikian ada sedikit hal yang perlu ditambahkan. Materi yang akurat dan mendalam merupakan kunci untuk meningkatkan penguasaan siswa dan mencapai kompetensi dasar (Departemen Pendidikan Nasional, 2008). Aspek penyajian materi masuk dalam kategori valid, menunjukkan bahwa materi sudah disajikan dengan baik dan informatif. Penyajian informasi yang tidak tepat akan menyebabkan siswa mengalami kesulitan memahami sehingga keinginan untuk belajar juga akan menurun (Alawiyah, Muldayanti, \& Setiadi, 2016). 
Hasil evaluasi terhadap materi menunjukkan bahwa ada banyak aspek yang perlu diperhatikan dalam menyusun modul diantaranya, konten disusun dengan benar dan tepat, topik yang disajikan sesuai pengalaman belajar yang diperlukan siswa, ruang lingkup materi sudah tepat, mutakhir dan mudah dipahami (Mulyati, 2002).Validasi dari segi media memperoleh nilai 98,2\% yang artinya modul sangat valid sehingga sangat layak untuk digunakan dan disebarluaskan (Arikunto, 2010). Komponen penilaian pada validasi media terdiri atas beberapa aspek terkait ciri modul diantaranya self contained, self instruction, adaptif, stand alone dan user friendly. Komponen dalam modul mampu mendukung ciri modul yang self instruction, hal ini ditunjukkan dengan adanya instruksi kegiatan belajar yang perlu dilakukan siswa dan penyediaan sarana pembelajaran melalui unit belajar. Modul juga bersifat self contained karena materi yang dijabarkan sudah memuat keseluruhan topik yang dijabarkan dalam KD 3.8 dan 4.8 sehingga cukup memenuhi meskipun tidak ditunjang dengan bahan ajar yang lain (Sungkono, 2003). Bahasa yang digunakan bersahabat dan tidak terlalu kaku sehingga berperan sebagai sahabat siswa dalam menuntun belajar disertai pula dengan informasi yang aktual sehingga lebih adaptif terhadap perkembangan IPTEK (Daryanto, 2013).

Uji keterbacaan bertujuan untuk mengetahui kemudahan modul untuk dipahami dan digunakan dalam pembelajaran (Dewi \& Arini, 2018). Nilai keterbacaan modul sebesar 83,5\% artinya modul cukup praktis untuk digunakan dan mudah dipahami (Akbar, 2013). Hasil ujicoba menunjukkan bahwa tampilan modul sudah cukup menarik, isi sudah lengkap dan mudah untuk digunakan. Tentunya hal tersebut tidak terlepas dari keberadaan komponen modul, seperti review tentang topik yang nantinya akan dibahas dalam modul, pendahuluan, langkah pembelajaran, ringkasan materi, soal tes atau latihan, rubrik penilaian, dan skor penilaian (Sungkono, 2003).

\section{SIMPULAN}

Berdasarkan hasil uji validasi dan uji keterbacaan, modul yang dikembangkan sudah layak untuk digunakan. Beberapa revisi dilakukan setelah melakukan uji coba dan diharapkan dapat meningkatkan kualitas modul yang telah dikembangkan. Uji coba modul sebaiknya dilakukan lebih lanjut dan perlu dilakukan implementasi melalui eksperimen agar dapat diketahui pengaruhnya pada pembelajaran. Produk yang telah teruji selanjutnya dapat disebarluaskan agar lebih bermanfaat.

\section{DAFTAR RUJUKAN}

Adnyana, B. P., \& Citrawathi, D. M. (2017). The Effectiveness of Question-Based Inquiry Module in Learning Biological Knowledge and Science Process Skills. International Journal of Environmental \& Science Education, 12(8), 1871-1878.

Aimon, H., \& Satrianto, A. (2015). Prospek Konsumsi dan Impor Kedelai di Indonesia Tahun 2015 - 2020. Jurnal Kajian Ekonomi, 3(5).

Akbar, S. (2013). Implementasi Perangkat Pembelajaran. Bandung: PT Remaja Rosdakarya.

Alawiyah, H., Muldayanti, N. D., \& Setiadi, A. E. (2016). Analisis Kesulitan Belajar Siswa Dalam Memahami Materi Invertebrata di Kelas X MAN 2 Pontianak. Jurnal Biologi Education, 3(2), 9-20.

Anam, K. (2015). Pembelajaran Berbasis Inkuiri Metode dan Aplikasi. Yogyakarta: Pustaka Pelajar.

Andrini, V. S. (2016). The Effectiveness of Inquiry Learning Method to Enhance. Journal of Education and Practice, 7(3), 3842.

Arikunto, S. (2010). Prosedur Penelitian : Suatu Pendekatan Praktik. (Edisi Revisi). Jakarta: Rineka Cipta.

Benny, A. K. (2011). Permasalahan, Tantangan, dan Peluang Pencapaian Swasembada Kedelai. Prosiding Seminar Nasional Hasil Penelitian Tanaman Aneka Kacang dan Umbi, 11-28. Pusat Penelitian dan Pengembangan Tanaman Pangan.

Branch, R. (2009). Instructional Design: The ADDIE Approach. London: Springer Science Business Media, LLC.

Budiono, E., \& Susanto, H. (2006). Penyusunan dan Penggunaan Modul Pembelajaran Berdasar Kurikulum Berbasis Kompetensi Sub Pokok Bahasan Analisa Kuantitatif untuk Solah-soal Dinamika Sederhana pada Kelas X Semesrter 1 SMA. Jurnal Pendidikan Fisika Indonesia, 4(2), 79-87.

Daryanto. (2013). Menyusun Modul Bahan Ajar untuk Persiapan Guru dalam Mengajar. Yogyakarta: Gava Media.

Dewi, E., Suyatna, A., \& Ertikanto, C. (2017). Efektivitas Modul dengan Model Inkuiri untuk Menumbuhkan Keterampilan Proses Sains Siswa pada Materi Kalor. Tadris: Jurnal Keguruan dan Ilmu Tarbiyah, 2(2), 105-110. https://doi.org/10.24042/tadris.v2i2.1901

Dewi, N. R., \& Arini, F. Y. (2018). Uji Keterbacaan pada Pengembangan Buku Ajar Kalkulus Berbantuan Geogebra untuk Meningkatkan Kemampuan Pemecahan Masalah dan Representasi Matematis. PRISMA, Prosiding Seminar Nasional Matematika, 1, 299-303.

Effiong, Ekpo, O., \& Charles, E. (2015). Impact of Instructional Materials In Teaching And Learning of Biology in Senior Secondary Schools In Yakurr Lg A. International Letters of Social and Humanistic Sciences, 62, $27-33$. https://doi.org/10.18052

Goldschmid, B., \& Goldschmid, M. L. (1973). For the Purpose of the Present Discussion a Module is Defined as : Higher Education, 2, 15-32.

Hapsari, R. T. (2014). Pendugaan Keragaman Genetik dan Korelasi Antara Komponen Hasil Kacang Hijau Berumur Genjah. Buletin Plasma Nutfah, 2(2).

Hutami, S., Mariska, I., \& Supriati, Y. (2006). Peningkatan Keragaman Genetik Tanaman melalui Keragaman Somaklonal. Jurnal AgroBiogen, 2(2), 81-88. 
Ikhsan, M., Sutarno., \& Prayitno, B. A. (2016). Pengembangan Modul Berbasis Inkuiri Terbimbing Pada Materi Sistem Gerak Manusia untuk Meningkatkan Hasil Belajar Siswa Kelas XI MIA SMA Negeri 1 Wera Kabupaten Bima Nusa Tenggara Barat. Jurnal Inkuiri, 5(1), 133-142.

Ismulyati, S., Khaldun, I., \& Munzir, S. (2015). Pengembangan Modul dengan Pembelajaran Kontekstual untuk Meningkatkan Motivasi dan Hasil Belajar Siswa pada materi Sistem Koloid. Jurnal Pendidikan Sains Indonesia, 3(1), $230-238$.

Jambormias, E., Sutjahjo, S. H., Jusuf, M., \& Suharsono. (2004). Keragaan, Keragaman Genetik dan Heritabilitas Sebelas Sifat Kuantitatif Kedelai (Glycine max L. Merrill) pada Generasi Seleksi F5 Persilangan Varietas Slamet X Nakhonsawan. Jurnal Pertanian Kepulauan, 3(2), 115-124.

Juniarta, A. T. (2016). Mengkaji Penerapan Kognitif dalam Tuntutan Psikomotorik pada Pembelajaran Pendidikan Jasmani. Prosiding Seminar Nasional Peran Pendidikan Jasmani Dalam Menyangga Interdisipliner Ilmu Keolahragaan, $228-239$. Universitas Negeri Malang.

Kashdan, T. B., Gallagher, M. W., Silvia, P. J., Winterstein, B. P., Breen, W. E., Terhar, D., \& Steger, M. F. (2009). The Curiosity and Exploration Inventory-II: Development, Factor Structure, and Psychometrics. Journal of Research in Personality, 43(6), 987-998. https://doi.org/10.1016/j.jrp.2009.04.011

Kementerian Pertanian. (2016). Outlook Komoditas Pertanian Tanaman Pangan Kedelai. Pusat Data dan Sistem Informasi Pertanian.

Kunandar. (2009). Guru Profesional Implementasi Kurikulum Tingkat Satuan Pendidikan (KTSP) dan Sukses dalam Sertifikasi Guru. Jakarta: Rajawali Press.

Kuswantoro, H., Artari, R., Rahajeng, W., Ginting, E., \& Agus, S. (2018). Genetic Variability, Heritability, and Correlation of Some Agronomical Characters of Soybean Varieties. Biosaintifika, 10(1), 9-15. https://doi.org/10.15294/biosaintifika.v10i1.9939

Lahadisi. (2014). Inkuiri: Sebuah Strategi Menuju Pembelajaran Bermakna. Al-Ta'dib, 7(2), 85-98.

Lasmiyati., \& Harta, I. (2014). Pengembangan Modul Pembelajaran untuk Meningkatkan Pemahaman Konsep dan Minat SMP Pythagoras, 9, 161-174.

Llewellyn, D. (2013). Teaching High School Science Through Inquiry and Argumentation. United States of America: Corwin.

Manurung, R. M. H. (2003). Upaya KhususTerobosan Pengembangan Produksi Agribisnis Kedelai. Jakarta: Direktorat Kacangkacangan dan Umbi-umbian.

Mulyati, Y. (2002). Pokok-Pokok Pikiran tentang Penulisan Modul Bahan Ajar dan Diklat. Disampaikan Dalam Pendidikan dan Latihan Bahasa Indonesia dan Bahasa Inggris Bagi Widyaiswara BPG, PPPG, dan Instruktur, pada Tanggal 15-25 Juni 2002 di PPPG Jalan Gardu, Srengseng. Pusat Pengembangan Penataran Guru Bahasa.

Mushtag, I., \& Khan, S. N. (2012). Factors Affecting Students' Academic Performance. Global Journal of Management and Business Research, 12(9).

Nurrohman, E., Zubaidah, S., \& Kuswantoro, H. (2017). Pengembangan Modul Pembelajaran Budidaya Tanaman Kedelai dengan Pendekatan Kontekstual untuk Siswa SMK Pertanian. Jurnal Penelitian Pendidikan, 2(7), $1003-1007$.

Prihatin, P., Prayitno, B. A., \& Rinanto, Y. (2017). Pengembangan Modul Berbasis Inkuiri Terbimbing pada Materi Jamur untuk Meningkatkan Kemampuan Berpikir Kritis Siswa Kelas X SMA Negeri 1 Cepogo Boyolali. Jurnal Inkuiri, 6(1), 75-90. https://doi.org/10.20961/inkuiri.v6i1.17268

Qodriyani, H. I., Sukiya, \& Wibowo, Y. (2017). Penyusunan Modul Sistem Reproduksi Manusia untuk Meningkatkan Hasil Belajar Kognitif dan Menanamkan Sikap Spiritual Peserta DidiK MAN Yogyakarta 1 Kelas XI Semester II. Jurnal Prodi Pendidikan Biologi, 6(3).

Rohmiyati, N., Ashadi, A., \& Utomo, S. B. (2016). Pengembangan Modul Kimia Berbasis Inkuiri Terbimbing pada Materi Reaksi Oksidasi-Reduksi. Jurnal Inovasi Pendidikan IPA, 2(2), 223 - 229.

Saleh, G., Abdullah, D., \& Anuar, A. R. (2002). Effects of Location on Performance of Selected Tropical Maize Hybrids development in Malaysia. Pertanika J. Trop. Agric. Sci, 25, 75-86.

Salim, K. D. (2015). Implementation of Structured Inquiry Based Model Learning Toward. International Journal of Research in Education and Science, 1(1), 75-83.

Santoso, E. (2017). Penggunan Model Pembelajaran Kontekstual untuk Meningkatkan Kemampuan Pemahaman Matematika Siswa Sekolah Dasar (Studi pada siswa kelas V SDN Sukarasa II Kecamatan Samarang Kabupaten Garut Tahun pelajaran 2014-2015 ). Jurnal Cakrawala Pendas, 3(1).

Sodikun., Sugiyarto., \& Prayitno, B. A. (2015). Pengembangan Modul Berbasis Inkuiri Terbimbing pada Materi Sistem Pencernaan Makanan untuk Meningkatkan Keterampilan Proses Sains. Seminar Nasional XII Pendidikan Biologi FKIP UNS. Surakarta.

Sugiyarto, \& Prayitno, B. . (2015). Pengembangan Modul Berbasis Inkuiri Terbimbing pada Materi Sistem Pencernaan Makanan untuk Meningkatkan Keterampilan Proses Sains. Surakarta.

Sungkono. (2003). Pengembangan dan Pemanfaatan Bahan Ajar Modul dalam Proses Pembelajaran. Yogyakarta: FIP UNY.

Terryana, R. T., Nugroho, K., Reflinur, Mulya, K., Dewi, N., \& Lestari, P. (2017). Keragaman Genotipik dan Fenotipik 48 Aksesi Kedelai Introduksi Asal Cina. Jurnal AgroBiogen, 13(1), 1-16. 